\title{
Characterization of Natural Gypsum Materials and Their Composites for Building Applications
}

\author{
Said Bouzit ${ }^{1}$, Said Laasri ${ }^{2, *}$, Mohamed Taha ${ }^{1}$, Abdelaziz Laghzizil ${ }^{3}$, Abdelowahed Hajjaji ${ }^{2}$, \\ Francesca Merli ${ }^{4}$ and Cinzia Buratti ${ }^{4, * \mathbb{C}}$ \\ 1 Faculty of Science, Ibn Zohr University, Agadir 80000, Morocco; saidbouzit19@gmail.com (S.B.); \\ taha1966@hotmail.com (M.T.) \\ 2 ENSA-El Jadida, Chouaib Doukkali University, El Jadida 1104, Morocco; hajjaji12@gmail.com \\ 3 Faculty of Sciences, Mohammed V University, Rabat 10010, Morocco; laghzizi@fsr.ac.ma \\ 4 Department of Engineering, University of Perugia, 06125 Perugia, Italy; merli@crbnet.it \\ * Correspondence: laasrisaid@yahoo.fr (S.L.); cinzia.buratti@unipg.it (C.B.); Tel.: +212-523-39-56-79 (S.L.)
}

Received: 3 April 2019; Accepted: 11 June 2019; Published: 14 June 2019

Abstract: Building retrofitting plays a key-role in energy saving and a growing interest is focused on insulating materials that allow a reduction in heat loss from envelopes with low thickness, by a process of reducing heating and cooling demand. In this context, a complete characterization of the physical properties of Moroccan natural gypsum materials was carried out. Basic information on the mineralogical, microstructure, thermal, mechanical, and acoustic characteristics of the rocks sampled from two Moroccan regions is provided. It was found that mineralogy, porosity, and water content are the main factors governing the development of the structure and the strength of the samples. The measured values of the porosity were $8.94 \%$, the water content varied between $2.5-3.0 \%$ for the two studied typologies, coming from Agadir and Safi, respectively. Gypsum powder was used for fabricating samples, which were investigated in terms of thermal and acoustic performance. Thermal properties were measured by means of a hot disk apparatus and values of conductivity of $0.18 \mathrm{~W} / \mathrm{mK}$ and $0.13 \mathrm{~W} / \mathrm{mK}$ were obtained for Agadir and Safi Gypsum, respectively. The acoustic performance was evaluated in terms of absorption coefficient and sound insulation, measured by means of a Kundt's Tube (ISO 10534-2). The absorption coefficients were slightly higher than the ones of conventional plasters with similar thickness. A good sound insulation performance was confirmed, especially for Safi Gypsum, with a transmission loss-value up to about $50 \mathrm{~dB}$ at high frequency.

Keywords: Moroccan gypsum; ultrasonic waves; Vickers hardness; gypsum plasters; thermal conductivity; acoustic performance

\section{Introduction}

Gypsum rocks are mainly used in the manufacture of plasters, cement, sulfuric acid, and other industrial applications, due to their low cost and aesthetics [1,2]. All modern homes in Morocco, as well as in other developed countries, use a great deal of wallboard for interior walls, while pure gypsum is used in glass making and other specialized industrial applications. In addition, plasterboards are among the building materials for thermal insulation and air purification in Moroccan buildings, but a high purity of natural gypsum products is desired in wallboard manufacturing, because the presence of impurities affects the gypsum properties [3]. However, the chemical composition of gypsum rock varies from one geographical site to another. Gypsum is primarily composed of $\mathrm{CaSO}_{4}$, associated with a wide assortment of accessory minerals, mainly carbonates, silica, and metal oxides $[4,5]$. The complete characterization of the raw material (as rock and powder) allows us to choose the best one to be used in the fabrication of plasters for building applications, with thermal and acoustic insulating purposes. 


\subsection{Thermal and Structural Characteristics: State of Art}

Thermal behavior of Moroccan gypsum material can depend on its whole rock geochemistry, but also on other features, such as morphology of the crystals, microstructure and mechanical properties. Several researchers have focused on natural gypsum for building applications. Among them, Tunisian researchers $[2,6,7]$ studied Tunisian gypsum, discovering that it presents an interesting behavior in terms of thermal insulation. The thermal conductivity of the Tunisian gypsum powder and plaster, measured with an experimental apparatus based on the radial flux meter, was $0.10 \pm 0.04 \mathrm{~W} / \mathrm{mK}$ and $0.22 \pm 0.03 \mathrm{~W} / \mathrm{mK}$, respectively [6]. However, the thermal performance of the plaster constituted of water and powder was strongly influenced by the mixing ratio: a negative effect of the presence of water was demonstrated on the plaster thermal insulation performance.

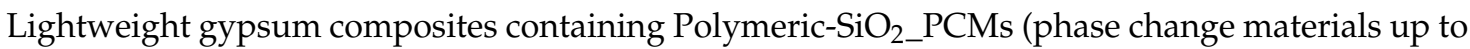
$15 \mathrm{wt} \%)$ were studied in [8]. As expected, the thermal insulation of the gypsum was improved $(+18.4 \%)$ by the thermoregulating effect of the PCM. Nevertheless, there was no variation in the crystal size and structure of the gypsum, as demonstrated by SEM analysis, with constant porosity despite the

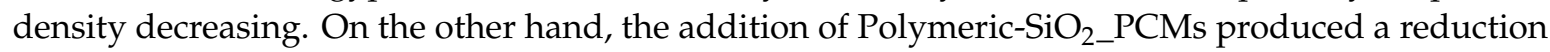
of mechanical properties (maximum flexural strength was reduced of about $45 \%$ with the $15 \mathrm{wt} \%$ ): however, they satisfied the European Regulation EN 13279-2 [9] standard.

Bicer and Kar [10] investigated the thermal and mechanical properties of gypsum plaster (calcium sulfate dehydrate) mixed with expanded polystyrene (EPS) $(20 \%, 40 \%, 60 \%$, and $80 \%$ percentages in weight) and tragacanth resin with adhesive characteristics $(0.5 \%, 1 \%$, and $1.5 \%$ by weight of the mixture). The thermal conductivity decreased up to $78.85 \%$ (with $80 \%$ of EPS) depending on the EPS ratio. The lowest thermal conductivity $(0.047 \mathrm{~W} / \mathrm{mK})$ was measured for $80 \%$ EPS and $1.5 \%$ resin content, which decreased in density due to the artificial pores that occurred later.

\subsection{Acoustical and Mechanical Characteristics: State of Art}

Noise insulation in building is also an important issue to be taken into account, in order to achieve optimal comfort conditions. The acoustic properties of plasters and concrete have been widely investigated in the literature [11-14]. Buratti et al. [11] studied the effect on the acoustic properties of innovative insulating coatings made of natural calk and granular silica aerogel, with a final coat of $2 \mathrm{~mm}$. They showed a better acoustic absorption coefficient when compared to the same plaster without granules. However, the $\alpha$-value strongly depends on the final coat; normal incidence values are not very high at all (about 0.13 , increased to 0.18 when removing the final coat). The acoustic absorption performance of clay-based plasters and natural earth of the north-western Sicily were investigated in [12]; they are mainly used for interior wall coatings in green buildings, as an alternative to the more common gypsum or lime plaster. Natural earth plasters are characterized by open porosity, higher than that of commercial materials, with a consequent increase in sound absorption, while premixed clay-based plasters do not show a marked difference in the absorption behavior. Moreover, for medium-high frequencies, the effectiveness of the noise mitigation seems to depend on the size of the sandy aggregate. However, the absorption performance of green-plasters is comparable to the one of traditional lime-based or gypsum-based binders and fired clay bricks.

In a recent study in 2018, Bozkurt and Demirkale [13] investigated the influence of mixtures produced with river sand aggregate and hydraulic lime binder on the absorption properties, considering the effects of volumetric ratio, aggregate particle sizes, and different types of additives. Results showed that by increasing the binder volume ratio, the sound absorption tends to decrease, but a positive effect on compressive and flexural strengths is highlighted. The size of the aggregate particles is also very important: the use of fine sand (particles in the $0-2 \mathrm{~mm}$ range) reduces the $\alpha$-values. Furthermore, it was found that polypropylene fiber, flax fiber, and crumb rubber additives in the mixture allow us to increase the sound absorption coefficient at low frequencies (up to $750 \mathrm{~Hz}, 900 \mathrm{~Hz}$, and $800 \mathrm{~Hz}$, respectively), with a reduction in compressive and flexural strengths (about $40-45 \%$ ). 
The acoustic properties of hemp concretes were investigated in [14] in terms of the absorption coefficient and sound insulation. The hemp-clay and hemp-lime mixtures are characterized by a similar acoustic behavior, in which binder fluidity and clay type have no effect. Considering densities below $375 \mathrm{~kg} / \mathrm{m}^{3}$, a peak of absorption equal to $0.6-1$ was measured in the $500-1200 \mathrm{~Hz}$; when the density increases above $500 \mathrm{~kg} / \mathrm{m}^{3}$, the sound absorption curve flattens, while the transmission loss increases. However, the width of the absorption peak and the air resistivity for a given density are lower for hemp-lime than for hemp-clay.

\subsection{Aim and Contents of the Paper}

The present investigation was carried out in order to identify the main physic-chemical characteristics of Moroccan gypsum rocks sampled from Agadir (AG) and Safi (SG) regions, located in southwestern Morocco, on the Atlantic Ocean. In order to study the structural and physical properties, the sampled gypsum minerals were dried and heated at different temperatures.

The powder obtained from the minerals was used for manufacturing plaster samples, which were characterized at Ibn Zohr University in Agadir-Morocco and at University of Perugia-Italy in terms of thermal and acoustic performance.

The following measurements were carried out: thermal conductivity by means of a hot disk apparatus, and absorption and insulation acoustic performance, by means of a Kundt's tube.

The thermal conductivity measurements were carried out with thermal flux meter methodologies. However, in many studies [15-17] the hot disk apparatus is used in order to evaluate the thermal properties of the materials, because of the small dimensions required for the samples and the quick tests, even if it is a more approximate approach with respect to the thermal flux meter method.

A precise measurement of the acoustic properties is normally performed in reverberating rooms, under sound diffuse field conditions, but it is very expensive and time-consuming, due to the amount of material needed for fabricating large samples. As an alternative, the acoustic tests can be carried out at normal incidence, in a traditional impedance tube. The two (absorption coefficient $\alpha$ ) and the four (transmission loss) microphones configuration were followed for the measurements on the Moroccan plasters, ranging from $100 \mathrm{~Hz}$ to $1600 \mathrm{~Hz}$ (large tube) and from $400 \mathrm{~Hz}$ to $5000 \mathrm{~Hz}$ (small tube) and the results were compared with traditional plasters.

\section{Materials and Methods}

The gypsum samples (Figure 1) investigated in this study come from Agadir (AG) and Safi (SG) ores, in southwestern Morocco, on the Atlantic Ocean. The gypsum natural rocks and grinded powders were firstly characterized in terms of thermo-gravimetric analysis and chemical composition, density and porosity, thermal conductivity, and mechanical properties.

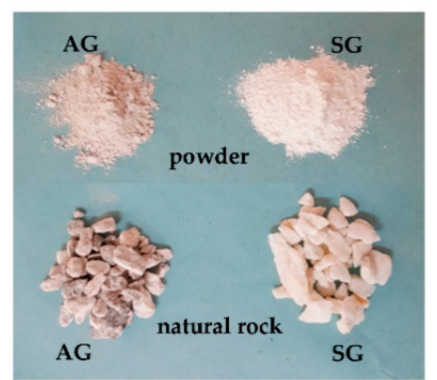

Figure 1. Samples of gypsum from Agadir (AG) and Safi (SG) (South-Western Morocco).

The acoustic performance of the material is also a very important aspect. A preliminary acoustic analysis was carried out, in order to identify the best site of the raw material, also in terms of acoustic behavior. Due to the difficulty in conducting acoustic tests on powder and natural rocks, samples were 
manufactured by mixing AG and SG-powders with water (mass ratio water/gypsum of 0.8 ) and dried, according to the thermal stability of the samples.

The main features of the samples investigated and the related tests are summarized in Table 1.

Table 1. Characteristics of the examined samples and the related tests.

\begin{tabular}{|c|c|c|c|}
\hline Test & Investigated Data & $\begin{array}{c}\text { AG and SG } \\
\text { Sample Material }\end{array}$ & Amount/Dimension \\
\hline $\begin{array}{l}\text { thermo-gravimetric } \\
\text { analysis }\end{array}$ & thermal stability & powder & about 2 gr \\
\hline chemical composition & $\begin{array}{l}\text { crystallographic structure and } \\
\text { Electron Microscopy Scanning (SEM) }\end{array}$ & powder & about 2 gr \\
\hline physical properties & density and porosity & $\begin{array}{l}\text { natural rock } \\
\text { powder }\end{array}$ & $\begin{array}{l}60 \mathrm{gr} \\
5 \mathrm{gr}\end{array}$ \\
\hline thermal performance & thermal conductivity & $\begin{array}{l}\text { natural rock } \\
\text { powder }\end{array}$ & $\begin{array}{c}59 \times 30 \times 8 \mathrm{~mm}^{3} \\
300 \mathrm{gr}\end{array}$ \\
\hline $\begin{array}{l}\text { mechanical properties } \\
\text { (ultrasonic waves) }\end{array}$ & $\begin{array}{l}\text { transversal and longitudinal speeds, } \\
\text { Young and shear modules, coefficient } \\
\text { of Poisson, Vickers hardness }\end{array}$ & natural rock & $\begin{array}{l}\text { small pieces and } \\
59 \times 30 \times 8 \mathrm{~mm}^{3}\end{array}$ \\
\hline Acoustic performance & $\begin{array}{c}\text { Absorption coefficient and } \\
\text { Transmission Loss }\end{array}$ & $\begin{array}{l}\text { gypsum powder mixed } \\
\text { with water and dried }\end{array}$ & $\begin{array}{l}\text { cylindrical } 29-\mathrm{mm} \text { and } \\
100-\mathrm{mm} \text { samples }\end{array}$ \\
\hline
\end{tabular}

\subsection{Thermo-Gravimetric Analysis and Chemical Composition}

Thermo-gravimetric and differential thermal analyses were carried out in airflow, using Thermal Analysis Instruments Netzsch STA-409EP equipment. They were performed under atmospheric air, from $30^{\circ} \mathrm{C}$ to $1000{ }^{\circ} \mathrm{C}$, with a heating rate of $10^{\circ} \mathrm{C} / \mathrm{min}$. The resulting solids were characterized using $\mathrm{X}$-ray powder diffraction (Bruker D8 Advanced diffractometer). Infrared spectra were recorded at a $2 \mathrm{~cm}^{-1}$ resolution, from $500 \mathrm{~cm}^{-1}$ to $4000 \mathrm{~cm}^{-1}$ on a Shimadzu FT-IR 8400 spectrometer. Electron microscopy scanning (SEM) was performed on carbon-coated samples, using a Cambridge Stereoscan 120 instrument at an accelerating voltage of $10 \mathrm{kV}$.

\subsection{Density and Porosity}

The value of the total porosity was calculated from the density of rock (named $\rho_{R}$ ) and of powder $\left(\rho_{\mathrm{P}}\right)$; density is in general given by:

$$
\rho=m /\left(v^{\prime}-v\right)
$$

where $\mathrm{m}$ is the mass of the sample and $v$ and $v^{\prime}$ are the volumes of the water before and after the introduction of the sample in a graduated cylinder, respectively. Density was measured for both rock and powder and the porosity was calculated by using the following equation:

$$
\mathrm{P}(\%)=100\left(1-\rho_{\mathrm{R}} / \rho_{\mathrm{P}}\right)
$$

The water content $\left(\mathrm{W}_{\mathrm{c}}\right)$ was measured by heating the sample to $150{ }^{\circ} \mathrm{C}$ (drying) for $24 \mathrm{~h}$, in order to evaporate the water; $\mathrm{W}_{\mathrm{c}}$ was obtained according to the following equation:

$$
\mathrm{W}_{\mathrm{C}}(\%)=100\left(\mathrm{~m}_{\mathrm{i}}-\mathrm{m}_{\mathrm{d}}\right) / \mathrm{m}_{\mathrm{d}}
$$

considering as $m_{i}$ and $m_{d}$ the initial wet sample and the final dry sample mass, respectively.

\subsection{Thermal Properties}

The thermal conductivity, the specific heat, and the thermal effusivity were measured using the Hot Disk Thermal Constants Analyzer Apparatus (Figure 2). 


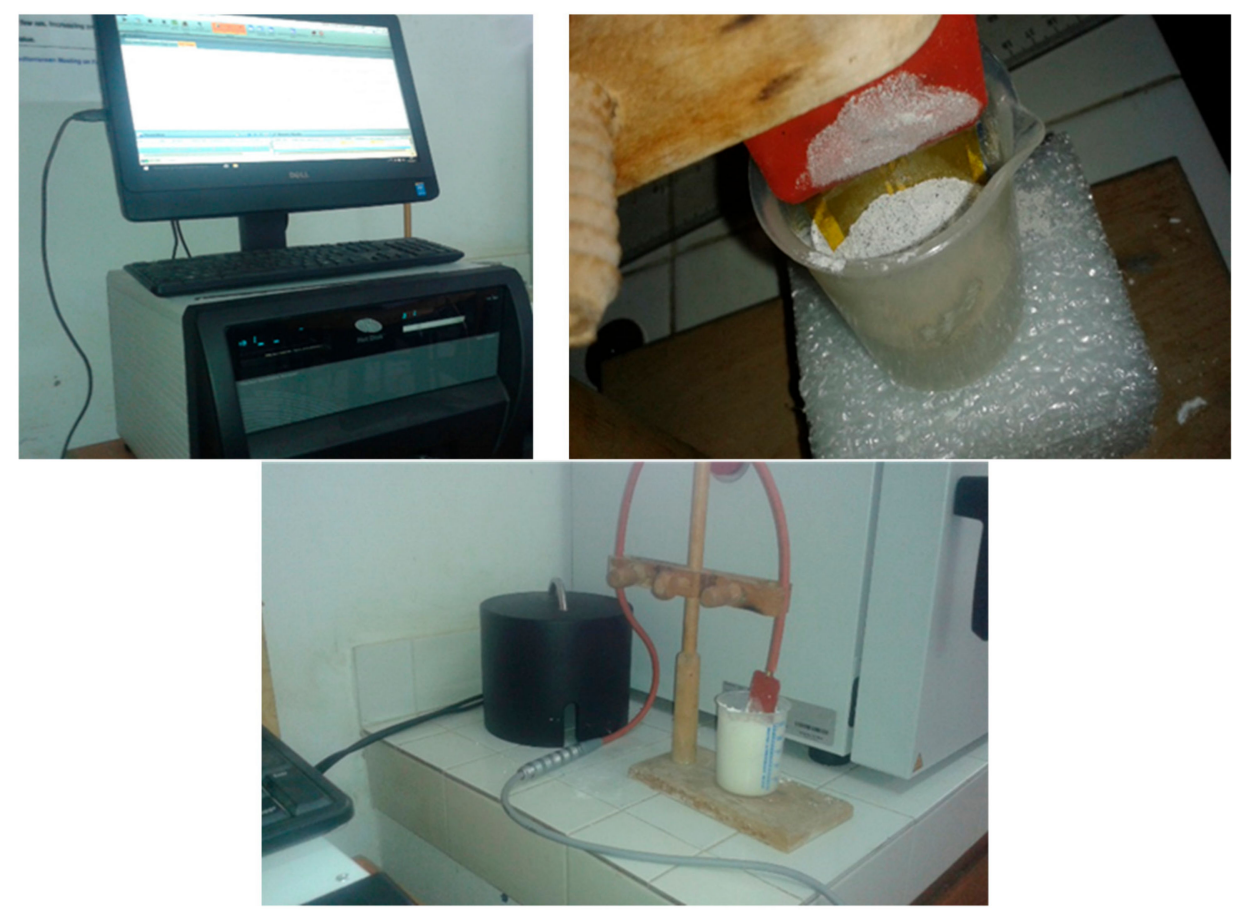

Figure 2. Hot disk thermal measurement method.

The principle consists in imposing a uniform heat flux in a plane, separating two symmetrical samples (powder in a backer) from a large extension with respect to the probe and by placing the probe between them (in the middle of the samples). For the rocks characterization, the probe was placed between the sample (upper side) and a polystyrene pane (lower side). The hot disk method is based on the evaluation of the temperature trend on the sensor surface that is simultaneously a heat generator and a temperature probe. It consists of a double $10 \mu \mathrm{m}$ thick nickel spiral, sandwiched between two sheets of Kapton or Mica insulation, depending on the operating temperature. The use of nickel makes the level of accuracy very high, thanks to its well-known temperature coefficient of resistivity. A constant electrical power is enabled into the probe; the heat is generated and the temperature variation is measured by the spiral sensor; the temperature raises on the sensor surface, and the generated heat and the thermal properties (thermal diffusivity and specific heat) of the material surrounding the probe are calculated [18]. When temperature of the sample increases, the electrical resistance increases too, and the thermal conductivity can be obtained by multiplying the thermal diffusivity a $\left(\mathrm{mm}^{2} / \mathrm{s}\right)$ and the specific heat $\gamma_{\mathrm{P}}\left(\mathrm{MJ} / \mathrm{m}^{3} \mathrm{~K}\right)$ measured by the hot disk.

In this study, the thermal conductivity tests were limited to room temperature $\left(20^{\circ} \mathrm{C}\right)$.

\subsection{Ultrasonic Waves and Mechanical Properties}

The ultrasonic technique allows us to measure the acoustic impedance and the speed of sound into a materials and therefore the actual mechanical characteristics, which are strongly related to the textural characteristics and chemical composition of crystals $[19,20]$. In order to measure the dispersion of the Lamb modes, a transmission technique was used by varying incidence angles for the ultrasonic waves. The ultrasound signals were created with a generator of short intensive pulses (Sofranel 5052 PR), which excited a broad band ultrasound emitter (Panametrics V 309), with a central frequency of $5 \mathrm{MHz}$ and they were sent through the samples.

Samples of AG and SG-natural rocks $\left(59 \times 30 \times 8 \mathrm{~mm}^{3}\right)$ were fabricated in order to evaluate the Poisson coefficient $v$ and Young modulus E. Waves transmitted at a constant pulse repetition frequency as a function of time were collected.

The Poisson coefficient $v$ and the Young's modulus E are related to the propagation of ultrasonic waves in contact with the gypsum sample, in particular to the longitudinal and transverse velocities 
of the ultrasonic waves $C_{L}$ and $C_{T}$, respectively [19]. The Poisson coefficient is linked to the ratio of longitudinal and transverse velocities as [21]:

$$
v=\frac{\left[\left[c_{\mathrm{L}} / \mathrm{C}_{\mathrm{T}}\right]^{2}-2\right]}{2\left[\left(\mathrm{C}_{\mathrm{L}} / \mathrm{C}_{\mathrm{T}}\right)^{2}-1\right]}
$$

From the Poisson's coefficient of each gypsum sample, its Young's modulus is expressed by [21]:

$$
\mathrm{E}=\frac{((1+v)(1-2 v))}{(1-v)} \rho \cdot C_{\mathrm{L}}^{2}
$$

where $\rho$ is the density of the sample. The shear coefficient is determined as a function of the density and the transverse velocity according to:

$$
\mathrm{G}=\rho \cdot \mathrm{C}_{\mathrm{T}}^{2}
$$

Some pieces of Agadir and Safi natural rocks were characterized by Vickers hardness tests. The Vickers indenter is a $136^{\circ}$ square-based diamond pyramid and the Vickers hardness (HV) is calculated as the relation between the applied load $\mathrm{F}$ and the impression surface and it is defined by the following equation $[20,22,23]$ :

$$
\mathrm{HV}=1.8544 \frac{\mathrm{F}}{d^{2}}
$$

where $d$ is the average length of the impression diagonal $(\mathrm{mm})$ measured by means of an integral microscope of the Vickers tester.

\subsection{Acoustic Performance}

The acoustic properties of samples manufactured by mixing each gypsum (Agadir and Safi) powders and water were measured by means of an impedance tube (Kundt's tube, Brüel \& Kjær, model 4206; 1/4 inch microphones Brüel \& Kjær, model 4187) available at the University of Perugia, according to ISO 10534-2 standard [24]. Cylindrical samples of AG and SG gypsums with diameters of $29 \mathrm{~mm}$ and $100 \mathrm{~mm}$ (Figure 3) were characterized in terms of sound absorption and sound insulation properties. For each kind of gypsum, two samples of the smaller-diameter were available for testing, while only one 100-mm-diameter sample was available, due to the difficulty in fabrication and transportation of the material without cracks and inhomogeneity.

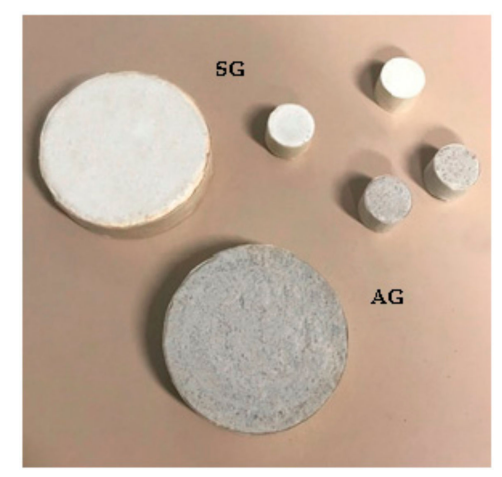

Figure 3. The investigated gypsum of Agadir and Safi cylindrical samples for the large and small tube.

The main features of the considered samples are reported in Table 2. The density of the samples was calculated weighing them with an electronic precision balance and assuming perfect cylinders of the specified diameter. The thicknesses of the $100 \mathrm{~mm}$ samples was higher than the ones of the $29 \mathrm{~mm}$ samples (about $25 \mathrm{~mm}$ compared to $21 \mathrm{~mm}$ ); the larger samples were characterized by a lower density (1630 and $1520 \mathrm{~kg} / \mathrm{m}^{3}$ for Agadir and Safi gypsum, respectively) with respect to the smaller 
ones, which have a density in the $1830-1870 \mathrm{~kg} / \mathrm{m}^{3}$ range. No significant difference was found between densities of the Agadir and Safi gypsums.

Table 2. Characteristics of the examined samples for acoustic measurements.

\begin{tabular}{cccc}
\hline Sample & Thickness $[\mathrm{mm}]$ & Diameter $[\mathrm{mm}]$ & Density $\left[\mathrm{kg} / \mathrm{m}^{\mathbf{3}}\right]$ \\
\hline AG-1_1 & 25.1 & 100 & 1630 \\
SG-1_1 & 25.6 & 100 & 1520 \\
AG-s_1 & 21.3 & 29 & 1860 \\
AG-s_2 & 21.6 & 29 & 1860 \\
SG-S_1 & 20.4 & 29 & 1830 \\
SG-s_2 & 20.9 & 29 & 1870 \\
\hline
\end{tabular}

The normal incidence absorption coefficient was measured in the 100-1600 Hz (large tube) and $400-5000 \mathrm{~Hz}$ (small tube) frequency range, using the transfer function method with a two microphone configuration, according to [24].

The sound pressure was measured at the same time in the two fixed microphone positions and the calculation of the transfer function between them $\left(\mathrm{H}_{12}\right)$ was carried out. The normal incidence absorption coefficient is given by Equation (8):

$$
\alpha=1-|r|^{2}
$$

where $r$ is the reflection factor depending on the transfer function for the incidence $\left(H_{I}\right)$ and the reflected $H_{R}$ wave, the wavenumbers $\left(K_{0}\right)$, and the distance between the top of the sample surface and the microphone position $x_{1}$, as shown in (9):

$$
\mathrm{r}=\left[\frac{H_{12}-H_{I}}{H_{R}-H_{12}}\right] \exp \left(2 i K_{0} x_{1}\right)
$$

A four microphone transfer function method is used in order to evaluate the acoustic insulation properties of the material (TL, transmission loss); TL is measured in the $400-5000 \mathrm{~Hz}$ frequency range by the two-load method, with two consecutive acquisitions for each sample at different conditions of the tube extremity (a reflective and an absorbing material are installed on the terminal part of the tube in each acquisition) $[25,26]$. TL is related to the sound transmission coefficient $\tau$ as:

$$
T L=10 \cdot \log (1 / \tau)
$$

The experimental apparatus in the large and small tube configurations during the acoustic absorption and transmission loss measurements is shown in Figure 4; several measurements for each sample were carried out for the same disk, by modifying their position inside the tube, and a mean value of $\alpha$ and TL were considered.
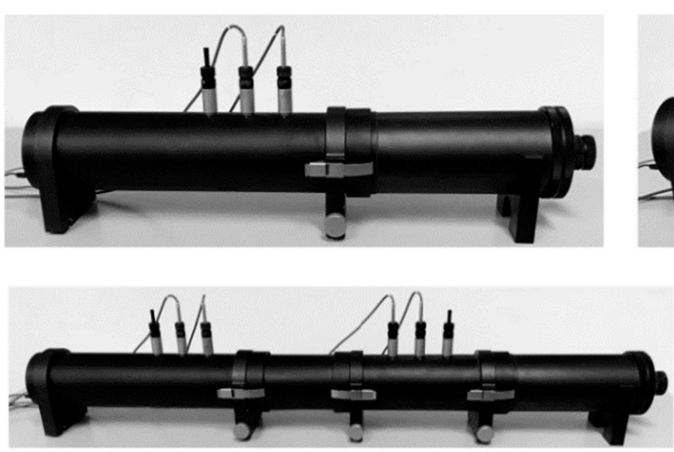

Figure 4. Normal incidence absorption coefficient (a) and transmission loss (b) measurements: large (left) and small (right) tube configurations.
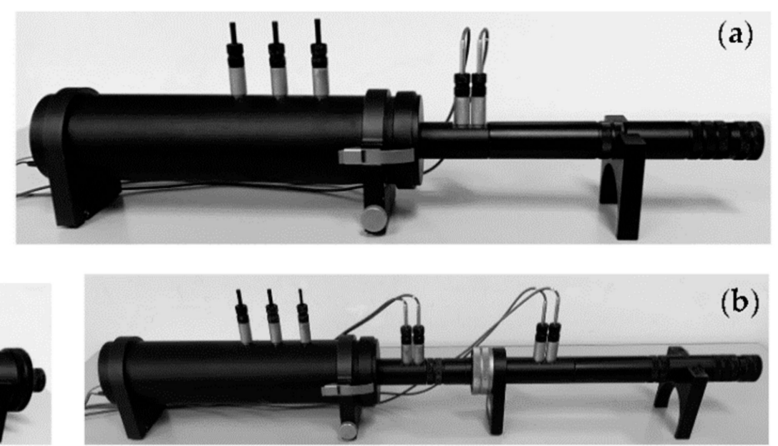

(b) 


\section{Results and Discussion}

\subsection{Thermal Analysis and Chemical Composition}

Thermal analysis techniques were firstly used to obtain information about thermal stability of natural Moroccan gypsum materials. A two-step dehydration process was suggested by a significant change in the slope of the weight loss curve (Figure 5). For the SG sample, the main thermal effect was observed at $140{ }^{\circ} \mathrm{C}$, with a total weight loss of $20.5 \mathrm{wt} \%$. The AG material presented two thermal effects: the first mass loss of 19 wt \% was observed before $160{ }^{\circ} \mathrm{C}$, assigned to water evaporation, whereas the second one was observed at $712{ }^{\circ} \mathrm{C}$, with a small weight loss of $3 \mathrm{wt} \%$ related to the combustion of little carbonates or organic matter, such as confirmed by chemical analyses.

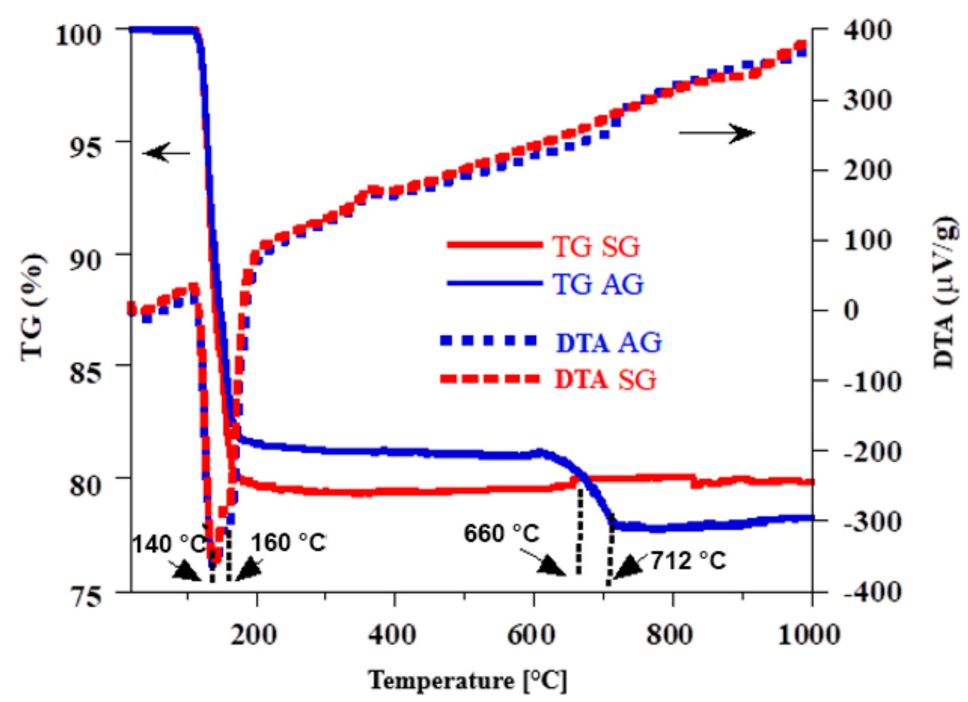

Figure 5. Thermal Gravimetric TG and Differential Thermal Analysis DTA curves for gypsum materials.

For both the natural gypsum samples, the main thermal effect corresponded to the conversion of dehydrated calcium sulphate $\mathrm{CaSO}_{4} 2 \mathrm{H}_{2} \mathrm{O}$ to the plaster $\mathrm{CaSO}_{4} 1 / 2 \mathrm{H}_{2} \mathrm{O}$, but the presence of oxide or carbonate impurities can affect this conversion.

The crystallographic structure of AG and SG samples was examined by XRD patterns, at different temperatures of calcination, in order to study the structural change during the dehydration phenomenon (Figure 6). The high intensity of the XRD peaks indicates that the AG and SG powders have a high crystallinity. Results show that the crystalline structure of these solids changed with the temperature of calcination. A pure $\mathrm{CaSO}_{4} 2 \mathrm{H}_{2} \mathrm{O}$ phase was detected for the two raw gypsum products, while the heat treatment between $150-360{ }^{\circ} \mathrm{C}$ favored the formation of a hemihydrates $\mathrm{CaSO}_{4} 1 / 2 \mathrm{H}_{2} \mathrm{O}$ monoclinic system. Beyond $360{ }^{\circ} \mathrm{C}$, an orthorhombic phase of anhydride $\mathrm{CaSO}_{4}$ was identified, such as that reported in $[27,28]$. The vaporization of the $\mathrm{H}_{2} \mathrm{O}$ molecule leads to the change of the crystalline structure and the formation of the anhydrous $\mathrm{CaSO}_{4}$.

Using FT-IR spectroscopy, the associated absorption bands of sulfate of gypsum were detected around $1120-1150 \mathrm{~cm}^{-1}$ and $669-604 \mathrm{~cm}^{-1}$, in addition to those of the stretching vibrations of the $\mathrm{H}_{2} \mathrm{O}$ molecules, between 355-3410 $\mathrm{cm}^{-1}$ (Figure 7). During dehydration, the intensities of the $\mathrm{OH}$ gypsum bands decreased strongly, until there was a total disappearance of the $\mathrm{OH}$-stretching vibrations. In increasing the dehydration temperature, the absorption bands of the $\mathrm{OH}\left(\mathrm{H}_{2} \mathrm{O}\right)$ shifted towards the high frequencies, with a maximum shift of $50 \mathrm{~cm}^{-1}$ when the temperature changed from $20^{\circ} \mathrm{C}$ to $150{ }^{\circ} \mathrm{C}$, traducing a strong structural transformation related to the dehydration process. 

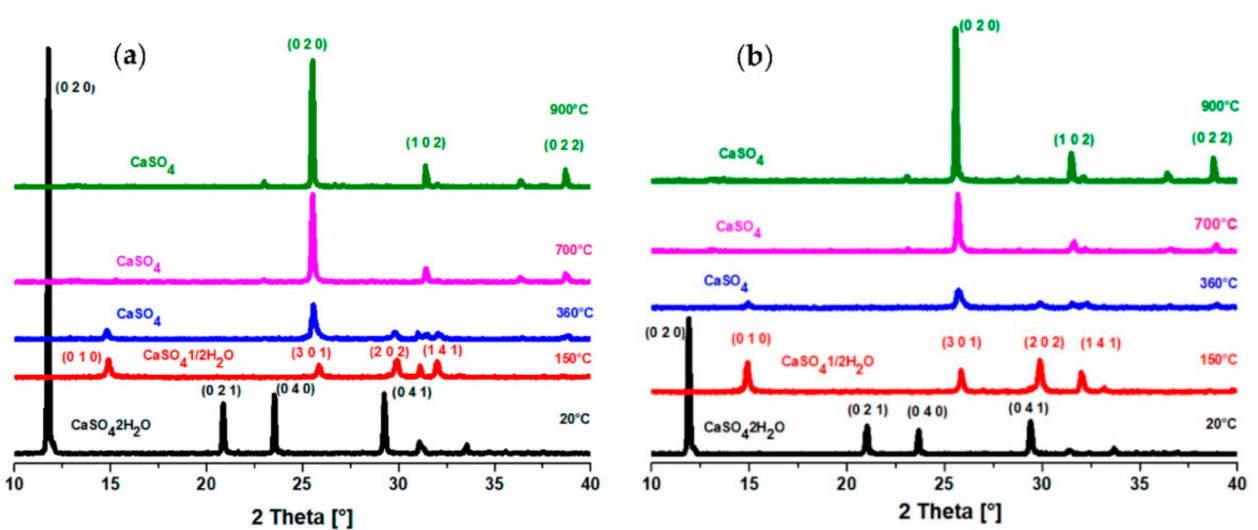

Figure 6. XRD diagrams of AG (a) and SG (b) minerals at different temperatures.

(a)

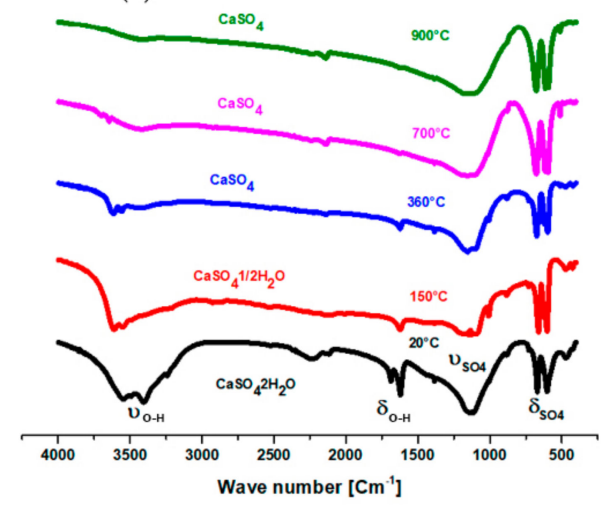

(b)

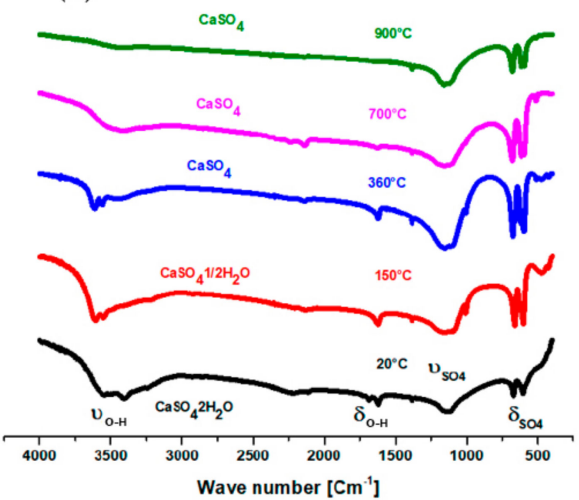

Figure 7. Infrared curves for Agadir (a) and Safi (b) gypsum at different temperatures.

SEM images of both gypsum samples at different temperatures of calcination show the needle shape structure related to the calcium sulphate crystals (Figure 8). For the uncalcined and calcined powder at $150{ }^{\circ} \mathrm{C}$ and $360^{\circ} \mathrm{C}$, there were less dense porous agglomerates. On the other hand, at a calcining temperature of $1100^{\circ} \mathrm{C}$, the two samples AG and SG showed denser agglomerates than the ones at lower temperatures. The shape of the agglomerates depends on the origin of the gypsum: the Safi sample showed round agglomerates, while the Agadir one presented needle agglomerates.
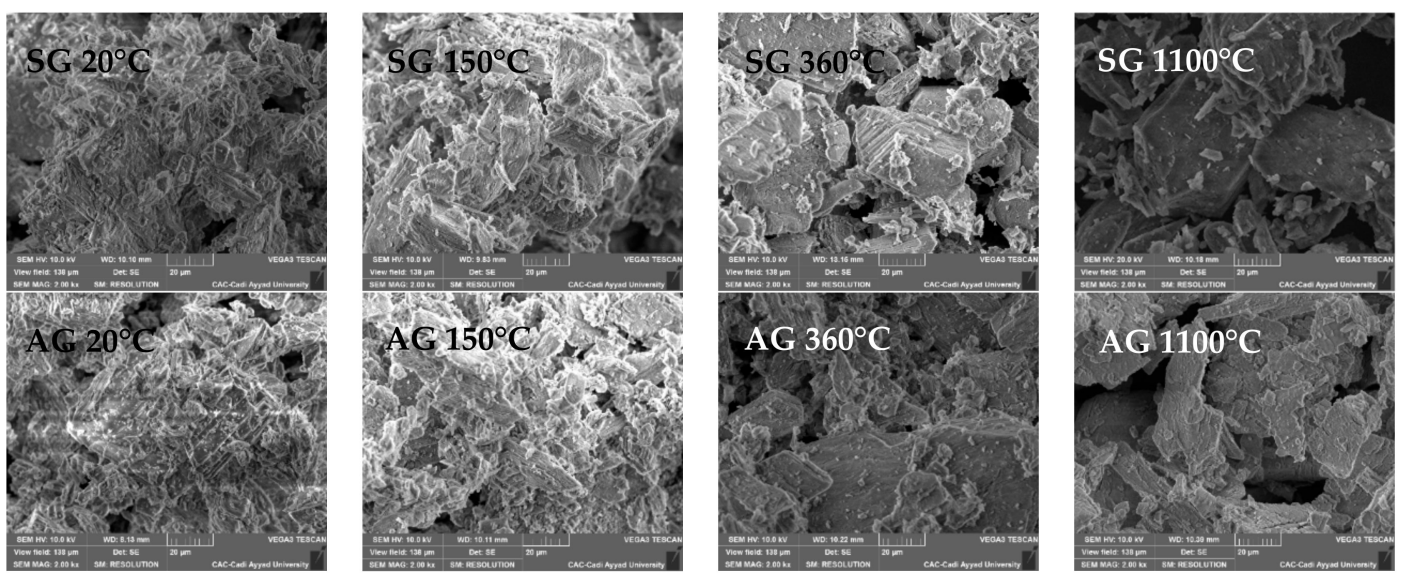

Figure 8. SEM images of SG and AG samples treated at various temperature of calcination.

The chemical composition of the SG and AG powders was measured via X-ray fluorescence spectroscopy (XRF) (Table 3). Results revealed that the weight percentages of the constituent elements varied between the two gypsum samples, confirming that the $\mathrm{CaO}$ and $\mathrm{SO}_{3}$ oxides are the major 
components of gypsum powder, but their content in the SG crystal is slightly higher. As listed in Table 3, the concentration of oxide impurities was more evident in the AG case, demonstrating that the Moroccan gypsum SG from the Safi region, consists mostly of calcium sulphate hydrate highly pure (often 98\%) and does not require any purification. Despite this little change in mineralogy between the two gypsum materials, they can be considered as pure gypsum materials that could be used in plaster making and other specialized industrial applications.

Table 3. Chemical composition of gypsum powders.

\begin{tabular}{cccccccccccc}
\hline$\%$ & $\mathrm{SO}_{3}$ & $\mathrm{CaO}$ & $\mathrm{SiO}_{\mathbf{2}}$ & $\mathbf{M g O}$ & $\mathrm{Al}_{\mathbf{2}} \mathbf{O}_{3}$ & $\mathrm{SrO}$ & $\mathrm{Fe}$ & $\mathbf{K}_{\mathbf{2}} \mathbf{O}$ & $\mathrm{Na}_{\mathbf{2}} \mathbf{O}$ & $\mathbf{I}$ & $\mathbf{C}$ \\
\hline $\mathrm{AG}$ & 46.6 & 28.8 & 1.69 & 0.83 & 0.77 & 0.250 & 0.175 & 0.187 & 0.10 & 0.024 & 5.59 \\
$\mathrm{SG}$ & 48.9 & 29.8 & 0.446 & 0.446 & 0.086 & 0.128 & - & - & - & 0.0215 & 5.58 \\
\hline
\end{tabular}

\subsection{Density and Porosity}

In order to evaluate the porosity and the density, and to study their influence on the mechanical properties of gypsum, measurements were carried out on both hydrated SG and AG samples. Porosity is one of the most important physical characteristics, governing the mechanical strength and density; it is influenced by the grain size, particle shape, and grain distribution. The values of rock density $\rho_{R}$, powder density $\rho_{P}$, porosity $P$, and water content $W_{c}$ of the studied gypsums are summarized in Table 4. It can be observed that the porosity of the SG sample was slightly higher than that of the AG sample, which also had higher water content; it is confirmed by SEM images (Figure 8), where it has a higher percentage of dark area (pores).

As expected, due to the higher porosity, the SG samples had a lower density.

Table 4. Density and porosity of Moroccan Agadir (AG) and Safi (SG) samples of rock and powder.

\begin{tabular}{ccccc}
\hline Gypsum & $\rho_{\mathbf{R}}\left[\mathrm{kg} / \mathrm{m}^{3}\right]$ & $\boldsymbol{\rho}_{\mathbf{P}}\left[\mathrm{kg} / \mathbf{m}^{3}\right]$ & $\mathbf{P}[\%]$ & $\mathbf{W}_{\mathbf{c}, \mathbf{P}}[\%]$ \\
\hline AG & 2384 & 2617 & 8.90 & 2.52 \\
SG & 2219 & 2437 & 8.94 & 2.98 \\
\hline
\end{tabular}

\subsection{Thermal Properties}

The thermal properties of natural rocks and powders showed a significant difference between the materials sampled from the two Moroccan sites (Table 5). The difference in thermal conductivity of powders (about $30 \%$ ) is probably due to their mineralogy; they exhibit a smaller difference in thermal conductivity when compared to rocks (about 20\%). The porous nature of the materials and the water content affect specific heat, density, and thermal conductivity [29]. Lower values of thermal conductivity were obtained for the powder when compared to the rock, due to the porous structure of gypsums. In addition, there is a substantial relationship between thermal conductivity and density [30,31]: thermal conductivity decreases when also density and water content decrease, with the lowest value obtained for the SG powder being $(0.1254 \mathrm{~W} / \mathrm{mK})$. The thermal conductivities of the Moroccan gypsum samples were lower when compared to the ones from Tunisia-Meknassi gypsum plaster $(0.22-0.27 \mathrm{~W} / \mathrm{mK})$ [6], especially for SG, which could be used as insulation material [32].

Table 5. Thermal characteristics of AG and SG rock and powder samples.

\begin{tabular}{ccccc}
\hline & \multicolumn{2}{c}{ AG } & \multicolumn{2}{c}{ SG } \\
\cline { 2 - 5 } & Rock & Powder & Rock & Powder \\
\hline Thermal conductivity $[\mathrm{W} / \mathrm{mK}]$ & 1.835 & 0.177 & 1.477 & 0.125 \\
Thermal diffusivity $\left[\mathrm{mm}^{2} / \mathrm{s}\right]$ & 0.882 & 0.147 & 0.628 & 0.123 \\
Specific heat $\left[\mathrm{MJ} / \mathrm{m}^{3} \mathrm{~K}\right]$ & 2.081 & 1.203 & 2.035 & 1.020 \\
Thermal effusivity $\left[\mathrm{Ws}^{1 / 2} /\left(\mathrm{m}^{2} \mathrm{~K}\right)\right]$ & 1954 & 460.8 & 1863 & 357.6 \\
\hline
\end{tabular}


A difference between the two samples was also noticed in terms of thermal diffusivity $\left(0.147 \mathrm{~mm}^{2} / \mathrm{s}\right.$ and $0.123 \mathrm{~mm}^{2} / \mathrm{s}$ for AG and SG, respectively). This is an important result in terms of thermal insulation, since a good insulating material must not only have a low thermal conductivity, but also be able to delay the heat transfer.

Thermal effusivity is also an interesting performance, describing the ability of a material to quickly dissipate heat from its surface as soon as ambient temperature decreases. AG gypsum has a higher thermal effusivity $\left(460.8 \mathrm{Ws}^{1 / 2} / \mathrm{m}^{2} \mathrm{k}\right)$ than SG gypsum $\left(357.6 \mathrm{Ws}^{1 / 2} / \mathrm{m}^{2} \mathrm{k}\right)$, so it is more suitable to retain heat for a longer time.

\subsection{Ultrasonic Waves and Mechanical Properties}

The ultrasonic technique was applied to the natural rock samples in order to evaluate their mechanical properties. The mechanical coefficients are useful in finite element simulations, to investigate the structural behavior of gypsum, in varying the temperature and the aging time, particularly to predict the formation of cracks.

Figure 9 shows the ultrasonic signals backscattered by SG and AG samples. It is clear that the reflected signal is composed of several echoes.

The speed of ultrasound, the mechanical properties of Moroccan gypsum rocks, and Vickers hardness are reported in Table 6.

The results showed a small mechanical change between the studied gypsum samples when considering the difference in mineralogy, density, water content, and porosity of the crystals. The strength characteristics are mainly related to physical properties of hardened gypsum, as total open porosity and arrangement of gypsum crystals [33]. The observed change is not directly related to the thermodynamic parameters, but connected to the existence of some impurities in the AG samples that improve the Young Modulus, Shear Module, and Vickers hardness coefficients.
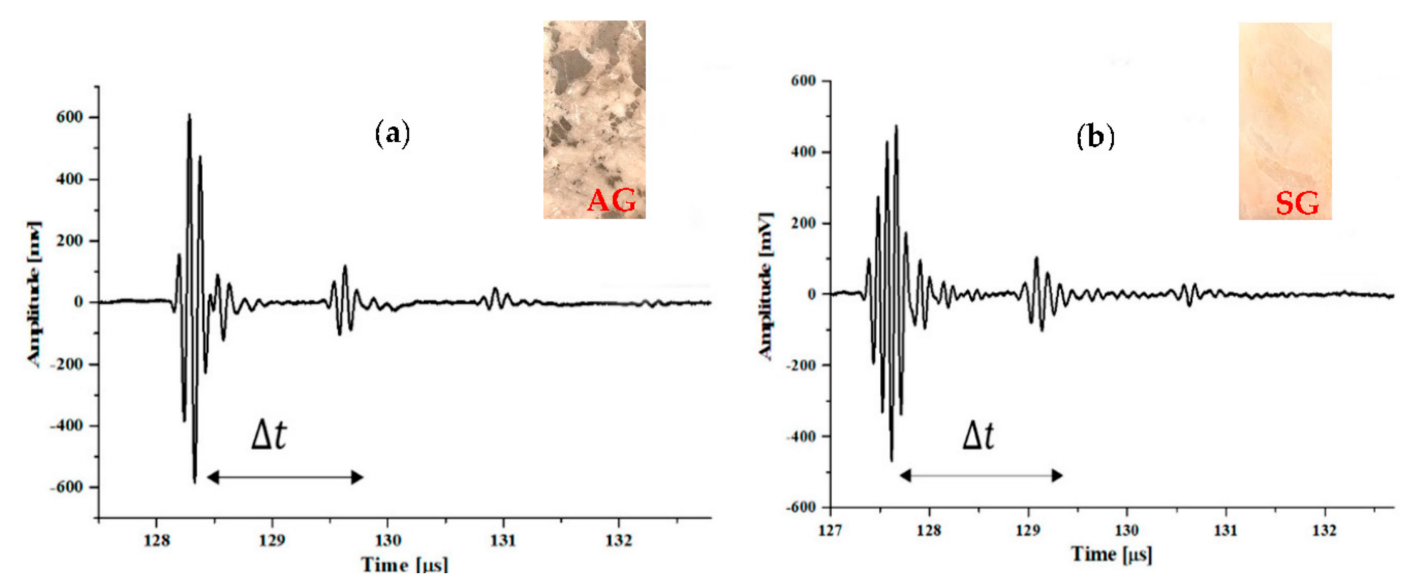

Figure 9. Transmission pulse echoes of AG (a) and SG (b) gypsum samples.

Table 6. Mechanical properties of the two Moroccan gypsum materials.

\begin{tabular}{ccccccc}
\hline Sample & $\begin{array}{c}\text { Transversal } \\
\text { Speed [m/s] }\end{array}$ & $\begin{array}{c}\text { Longitudinal } \\
\text { Speed [m/s] }\end{array}$ & $\begin{array}{c}\text { Young Module } \\
\text { [MPa] }\end{array}$ & $\begin{array}{c}\text { Shear Module } \\
\text { [MPa] }\end{array}$ & $\begin{array}{c}\text { Coefficient } \\
\text { of Poisson }\end{array}$ & $\begin{array}{c}\text { Vickers } \\
\text { Hardness }\end{array}$ \\
\hline AG & 2724.5 & 5066 & 45.8 & 17.7 & 0.29 & 16.6 \\
SG & 2722.1 & 5057 & 42.4 & 16.4 & 0.29 & 12.1 \\
\hline
\end{tabular}

\subsection{Acoustic Performance}

The average normal incidence absorption coefficient vs. frequency of the two samples is shown in Figure 10; due to the different thickness of the $100 \mathrm{~mm}$ and $29 \mathrm{~mm}$ samples (about $25 \mathrm{~mm}$ and $21 \mathrm{~mm}$, respectively), the large and small tube measurements cannot be combined. In the 100-1600 Hz frequency range (large tube, Figure 10a), the gypsum of Safi was characterized by a peak of absorption 
of 0.1 at about $600 \mathrm{~Hz}$; for the AG sample, the $\alpha$-peak decreased to 0.08 at the same frequency. The absorption performance of the samples was a little bit better than the ones of a conventional cement plaster $30 \mathrm{~mm}$ thick (dotted line in Figure 10a, $\alpha$-peak $\approx 0.05$, measured with the same apparatus); as expected, the first peak of the absorption curve moved to lower frequencies (about $400 \mathrm{~Hz}$ ) due to the higher thickness, according to [34].

In the overlap frequency range $(400-1600 \mathrm{~Hz})$ of the tubes, the absorption coefficients of the large samples were higher, due to their lower density, as expected according to the literature [24]. In the small tube $(400-5000 \mathrm{~Hz})$ the absorption curves of the two gypsum samples were very similar (maximum difference of about 0.02 at high frequency), as shown in Figure 10b.

The transmission loss trends for AG and SG are plotted in Figure 11 for the large $(100-1700 \mathrm{~Hz}$, Figure 11a) and small (400-5000 Hz, Figure 11b) tube configurations. In general, an increasing value of the transmission loss is observed when the thickness, the surface mass, and the density of the samples raise: the large samples, characterized by a lower density, at a fixed frequency show a TL value slightly lower than the small samples, as expected. However, both the specimens show the same trend of the curve: when comparing the AG and SG samples, in the entire frequency range (400-5000 Hz, small tube), the TL-values of SG are 8-10 dB higher than the ones of AG. In general, both the samples were characterized by good sound insulation performance; TL-values of AG were in the 32-36 dB range, while for SG the transmission loss grew up to $48 \mathrm{~dB}$ at $5000 \mathrm{~Hz}$.
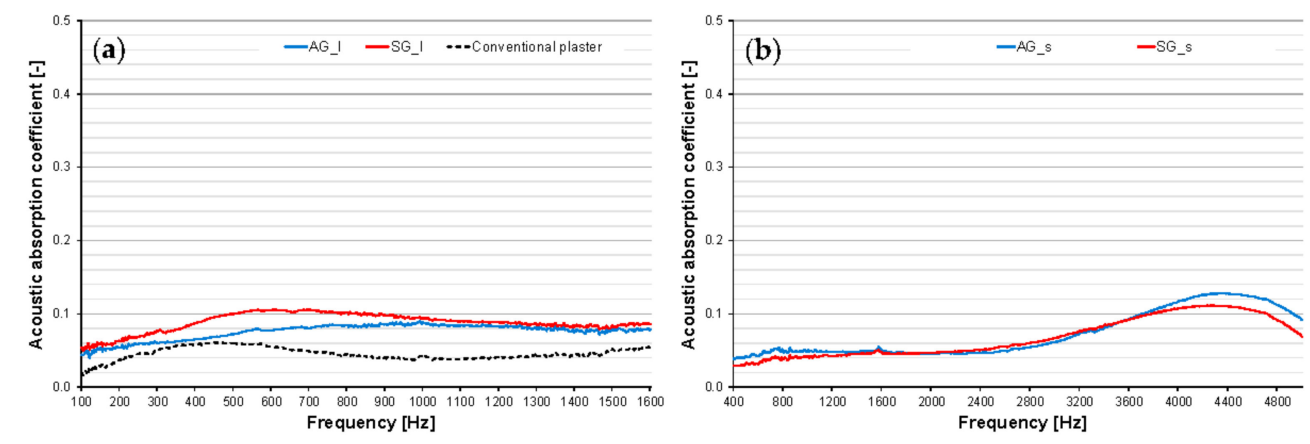

Figure 10. Normal incidence absorption coefficient of AG and SG samples: (a) large tube (100-1600 Hz) and (b) small tube $(400-5000 \mathrm{~Hz})$ measurements.
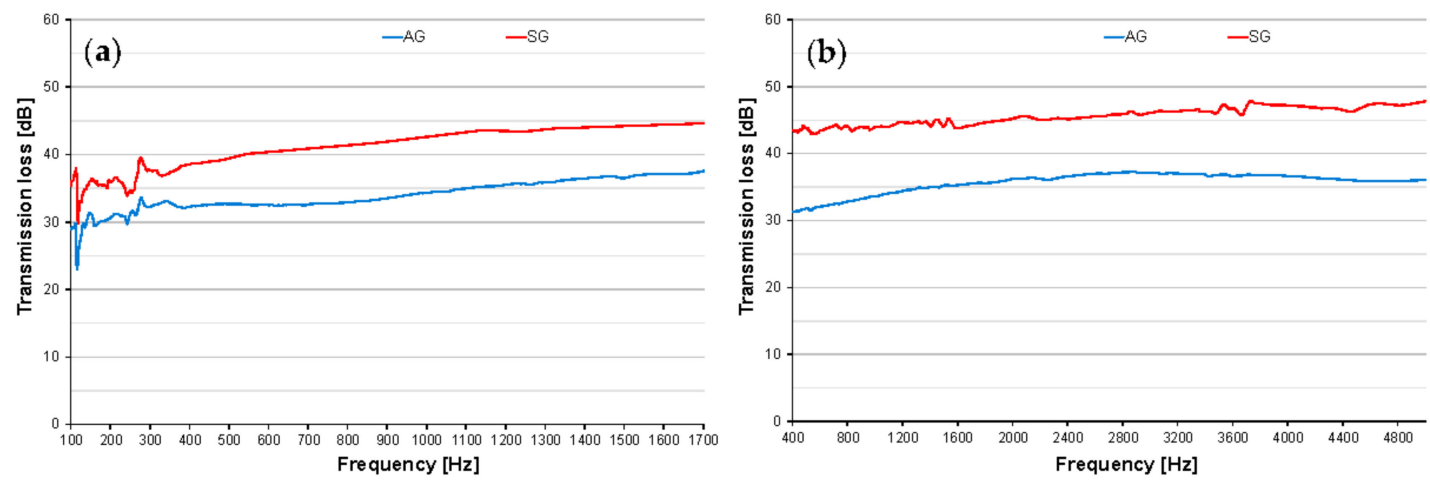

Figure 11. Normal incidence Transmission Loss of AG and SG samples: (a) large tube and (b) small tube.

\section{Conclusions}

The structural, thermal, and mechanical properties of Moroccan gypsum rocks sampled from the Agadir and Safi regions was studied in order to suggest the use of natural gypsum materials for sustainable building and refurbishment.

The different analytical techniques used in this characterization work show that the two gypsum samples (from the Agadir and Safi regions, Morocco) have almost the same mineralogy, excluding heavy metals considered as toxic elements and the formation of the various allotropic varieties at 
different temperatures. The sampled gypsum materials have very good thermal properties, able to ensure integrity in construction, especially thermal insulation, fire protection, bulk density, high water content and porosity, and low-cost in the market.

The acoustic properties (absorption coefficient and transmission loss at a normal incidence) were also measured by means of a Kundt's Tube (ISO 10534-2). The acoustic absorption coefficients were not very high for both the samples and they were comparable to the ones of conventional cement plasters. However, a very good sound insulation performance was achieved: the best properties were obtained for the Safi gypsum (TL $=48 \mathrm{~dB}$ at about $5000 \mathrm{~Hz}$ ), whereas for the Agadir gypsum the maximum value was $36 \mathrm{~dB}$ at a lower frequency (about $2900 \mathrm{~Hz}$ ).

Possible industrial applications for the gypsum industry indicated that gypsum from the Safi site has the required technical specifications. The comparison with Agadir gypsum has confirmed its interesting properties.

In that direction, it is possible to propose a new study to develop new products based on gypsum from the Safi SG, as well as to improve current gypsum. In this perspective, several plasters were manufactured adding different insulating materials or natural fibers into Safi gypsum matrix and their chemical, physical, thermal, mechanical, and acoustic properties will be studied. In particular, the use of natural materials as building components is very important, in order to reduce the environmental impact of the construction systems. The measurements are now a work in progress and will be the subject of future papers. This paper is the basis necessary for the raw material characterization and for the choice of the best one. Furthermore, this is a promising area that adds value to the energy saving sector; these materials are suitable solutions for retrofitting buildings, thanks to their good thermal behavior with very low thicknesses, also having good mechanical and acoustic properties.

Author Contributions: Conceptualization, C.B. and M.T.; methodology, C.B. and A.L.; investigation, F.M., S.B. and S.L.; writing - original draft preparation, F.M., S.B. and S.L.; writing-review and editing, C.B., A.H. and A.L.; supervision, C.B. and M.T.

Funding: This research received no external funding.

Acknowledgments: The authors thank El OUACHA and M. EZAHRI from University Ibn Zohr Agadir (Morocco) for ultrasonic and thermal analyses.

Conflicts of Interest: The authors declare no conflict of interest.

\section{References}

1. Strydom, C.A.; Groenewald, E.; Potgieter, J.H. Thermogravimetric studies of the synthesis of cas from gypsum, $\mathrm{CaSO}_{4} \cdot 2 \mathrm{H}_{2} \mathrm{O}$ and phosphogypsum. J. Therm. Anal. 1997, 49, 1501-1507. [CrossRef]

2. Mahmoudi, S.; Bennour, A.; Chalwati, Y.; Souidi, K.; Thabet, M.; Srasrad, E.; Zargouni, F. Tunisian Gypsums: Characteristics and use in cement. J. Afr. Earth Sci. 2016, 121, 267-273. [CrossRef]

3. Roszczynialski, W.; Gawlicki, M.; Nocuń Wczelik, W. Production and Use of By-Product Gypsum in the Construction Industry. Waste Materials Used in Concrete Manufacturing; William Andrew: Norwich, NY, USA, 1996; pp. 53-141.

4. Singh, R.N.; Eksi, M. Rock characterization of gypsum and marl. Int. J. Min. Sci. Technol. 1987, 6, 105-112. [CrossRef]

5. Green, H.; Gleadow, A.; Finch, D.; Hergt, J.; Ouzman, S. Mineral deposition systems at rock art sites, Kimberley, Northern Australia Field observations. J. Archaeol. Sci. Rep. 2017, 14, 340-352. [CrossRef]

6. Ben Mansour, M.; Soukaina, S.; Benhamou, B.; Ben Jabrallah, S. Thermal characterization of a Tunisian gypsum plaster as construction material. Energy Procedia 2013, 42, 680-688. [CrossRef]

7. Sdiri, A.; Bouaziz, S.; Sekrafi, A. Properties of Mestaoua evaporites (southern Tunisia) for plaster industry. Carbonates Evaporites 2017, 32, 195-204. [CrossRef]

8. Borreguero, A.M.; Serrano, A.; Garrido, I.; Rodriguez, J.F.; Carmona, M. Polymeric-SiO 2 -PCMs for improving the thermal properties of gypsum applied in energy efficient buildings. Energy Convers. Manag. 2014, 87, 138-144. [CrossRef] 
9. EN 13279-2. Gypsum Binders and Gypsum Plasters-Part. 2: Test. Methods; BSI: Northwood, Santry Dublin, Ireland, 2014.

10. Bicer, A.; Kar, F. Thermal and mechanical properties of gypsum plaster mixed with expanded polystyrene and tragacanth. Therm. Sci. Engin. Progr. 2017, 1, 59-65. [CrossRef]

11. Buratti, C.; Moretti, E.; Belloni, E.; Agosti, F. Development of Innovative Aerogel Based Plasters: Preliminary Thermal and Acoustic Performance Evaluation. Sustainability 2014, 6, 5839-5852. [CrossRef]

12. Randazzo, L.; Montana, G.; Hein, A.; Castiglia, A.; Rodonò, G.; Donato, D.I. Moisture absorption, thermal conductivity and noise mitigation of clay based plasters: The influence of mineralogical and textural characteristics. Appl. Clay Sci. 2016, 132-133, 498-507. [CrossRef]

13. Bozkurt, T.S.; Demirkale, S.Y. The laboratory analyses for the plasters prepared with river sand aggregate and hydraulic lime binder. Constr. Build. Mater. 2018, 190, 691-709. [CrossRef]

14. Dagrave-Lemeurs, M.; Glé, P.; de Menibus, A.H. Acoustical properties of hemp concretes for building thermal insulation: Application to clay and lime binders. Constr. Build. Mater. 2018, 160, 462-474. [CrossRef]

15. Singh, R.; Saxena, N.S.; Chaudhary, D.R. Simultaneous measurement of thermal conductivity and thermal diffusivity of some building materials using the transient hot strip method. J. Phys. D Appl. Phys. 1985, 18, 1-8. [CrossRef]

16. Log, T.; Gustafsson, S.E. Transient plane source (TPS) technique for measuring thermal transport properties of building materials. Fire Mater. 1995, 19, 43-49. [CrossRef]

17. Gustavsson, M.; Karawacki, E.; Gustafsson, S.E. Thermal conductivity, thermal diffusivity, and specific heat of thin samples from transient measurement with the hot disk sensor. Rev. Sci. Instrum. 1994, 65, 3856-3859. [CrossRef]

18. He, Y. Rapid thermal conductivity measurement with a hot disk sensor-Part 1 . Theoretical considerations. Thermochim. Acta 2005, 436, 122-129. [CrossRef]

19. Yasar, E.; Erdogan, Y. Correlating sound velocity with the density, compressive strength and Young's modulus of carbonate rocks. Int. J. Rock Mech. Min. Sci. 2004, 41, 871-875. [CrossRef]

20. Ben Ghorbal, G.; Tricoteaux, A.; Thuault, A.; Louis, G.; Hicot, D. Comparison of conventional Knoop and Vickers hardness of ceramic materials. J. Eur. Ceram. Soc. 2017, 37, 2531-2535. [CrossRef]

21. El Abassi, D.; Faiz, B.; Ibhi, A.; Aboudaoud, I. Characterization and Classification of Rocks with Lamb Modes. Int. J. Geosci. 2012, 3, 565-573. [CrossRef]

22. Baino, F.; Verné, E. Production and Characterization of Glass-Ceramic Materials for Potential Use in Dental Applications: Thermal and Mechanical Properties, Microstructure, and In Vitro Bioactivity. Appl. Sci. 2017, 7, 1330. [CrossRef]

23. Laasri, S.; Taha, M.; Hlil, E.K.; Laghzizil, A.; Hajjaji, A. Manufacturing and mechanical properties of calcium phosphate biomaterials. Comptes Rendus Mec. 2012, 340, 715-720. [CrossRef]

24. ISO 10534-2. Acoustics-Determination of Sound Absorption Coefficient and Impedance in Impedance Tubes-Part. 2: Transfer-Function Method; ISO: Geneva, Switzerland, 1998.

25. Jung, S.S.; Kim, Y.T.; Lee, Y.B.; Cho, S.; Lee, J.K. Measurement of sound transmission loss by using impedance tubes. J. Korean Phys. Soc. 2008, 53, 596-600. [CrossRef]

26. Long, M. Sound Transmission Loss, Architectural Acoustics, 2nd ed.; Elsevier: Amsterdam, The Netherlands, 2014; pp. 150-162.

27. Bezou, C.; Nonat, A.; Mutin, J.C.; Christensen, A.N.; Lehmann, M.S. Investigation of the crystal structure of gamma-CaSO${ }_{4}, \mathrm{CaSO}_{4} \frac{1}{2} \mathrm{H}_{2} \mathrm{O}$ and $\mathrm{CaSO}_{4} 0.6 \mathrm{H}_{2} \mathrm{O}$ by powder diffraction methods. J. Solid State Chem. 1995, 117, 165-176. [CrossRef]

28. Comodi, P.; Nazzareni, S.; Zanazzi, P.F.; Speziale, S. High-pressure behavior of gypsum: A single-crystal X-ray study. Am. Miner. 2008, 93, 1530-1537. [CrossRef]

29. Singh, N.B.; Middendorf, B. Calcium sulphate hemihydrate hydration leading to gypsum crystallization. Progr. Crys. Growth Charact. Mater. 2007, 53, 57-77. [CrossRef]

30. Ang, C.N.; Wang, Y.C. The effect of water movement on specific heat of gypsum plaster board in heat transfer analysis under natural fire exposure. Constr. Build. Mater. 2004, 18, 505-515. [CrossRef]

31. Thomas, G. Thermal properties of gypsum plaster board at high temperatures. Fire Mater. 2002, 26, 37-45. [CrossRef]

32. Zhank, Y.C.; Dai, S.B.; Huang, J.; Duan, S.G.; Zhi, Z.Z. Preparation of thermal insulation plaster with FGD gypsum. Kem. Ind. 2016, 65, 283-288. [CrossRef] 
33. Singh, M.; Garg, M. Relationship between mechanical properties and porosity of water-resistant gypsum binder. Cem. Concr. Res. 1996, 26, 449-456. [CrossRef]

34. Merli, F.; Anderson, A.M.; Carroll, M.K.; Buratti, C. Acoustic measurements on monolithic aerogel samples and application of the selected solutions to standard window systems. Appl. Acoust. 2018, 142, 123-131. [CrossRef] 